\title{
Bibliografía sobre fray Luis de León
}

LAZCANO GONZÁlez, RAFAEL, Fray Luis de León. bibliografía (=Colección Guía Bibliográfica 1), Editorial Revista Agustiniana, Madrid 1990, 17 x 24,278 p.

Con motivo del cuarto centenario de la muerte de Fray Luis de León (1591-1991), Rafael Lazcano ha tenido el gran acierto de publicar esta bibliografía, que supera con creces todas las anteriores. La sola enumeración de las VI secciones en que está dividida da idea de lo acabado de la obra:

I. Siglas y abreviaturas. II. Fuentes. III. Manuscritos (castellanos y latinos). IV. Ediciones y traducciones. V. Estudios: 1. Generales. 2. Sobre la vida. 3. Interpretación y crítica. 4. Fuentes. 5. Lenguaje. 6. Crítica textual. 7. Poesía. 8. De los nombres de Cristo. 9. La perfecta casada. 10. Estudios bíblicos. 11. Otras obras. 12. Filosofía. 13. Teología. 14. Espiritualidad y mística. 15. Fray Luis y el descubrimiento de América. 16. Relación con otros autores (Juan de la Cruz, Teresa de Ávila, Garcilaso, Lope de Vega, Unamuno, etc.). 17. Influencia y difusión. 18. Centenarios y homenajes. VI. Índices (cronológico, onomástico y general).

Son en total 1.505 papeletas perfectamente clasificadas. Un manual imprescindible para todo el que quiera estudiar a Fray Luis.

$\mathrm{Si}$ se leen las papeletas recogidas en el apartado "Relaciones con otros autores", se verá que, en su mayoría estarían mejor en Fuentes (Garcilaso, Teresa de Jesús, Scoto...) o en Influencias (Juan de la Cruz, Cervantes, Quevedo, Unamuno...). En Relaciones deberían figurar sólo las referentes a aquellas personas con las que Fray Luis tuvo trato: Arias Montano, Juan de Guevara... Al no tener ningún apartado especial, esperaríamos que los estudios sobre los sonetos estuvieran en Otros poemas, pero no es así, y quien no los conozca creerá que no se ha escrito nada sobre ellos.

$\mathrm{El}$ autor ha excluido, por principio, los artículos publicados en periódicos. Tengo mis dudas sobre la validez de este procedimiento. En la prensa aparecen artículos muy valiosos, así como los hay baladíes en revistas de 
prestigio. ¿Por qué dejar aquéllos y recoger, en cambio, éstos? En la raíz de esta manera de proceder están ciertos prejuicios inveterados, dos fundamentalmente, contra la prensa.

La historia, así se decía, es asunto del pasado. La actualidad, y nada más actual que un periódico, quedaba fuera de ella. Y así se miraba despectivamente la prensa, mientras se ponían los ojos en blanco ante cualquier papelucho encontrado en los archivos. No están lejanos los tiempos en que estaba socialmente prohibido estudiar a los autores que aún vivían y hasta era mal visto por algunos citarlos en las investigaciones. Hoy los estudios históricos de todo tipo han entrado, como debe ser, en el presente, que es lo que más nos interesa conocer. Hoy se estudia la prensa del pasado y del presente y se le da cabida en las bibliografías. En este mismo libro se recogen algunas papeletas sobre la presencia de Fray Luis en los periódicos de otros siglos, imprescindibles para conocer el favor de que gozaba y su influencia. ¿Por qué eliminar la prensa de nuestra época? ¿Para dar trabajo a los venideros? Nos interesa y mucho saber de qué se habla y se escribe y cuáles son los autores del pasado que aún siguen presentes; saber qué cabida sigue teniendo Fray Luis en nuestro tiempo.

El otro prejuicio prosperó de manera especial en determinados ambientes. La prensa es banal, intrascendente. Fruslerías. Por principio, nada de lo que en ella apareciera tenía interés. Pero la nómina de autores que han colaborado en la prensa y en ella han dejado huellas imborrables es abrumadora. Algunos han tenido la suerte de que sus trabajos hayan sido recogidos posteriormente en libros. Otros muchos se han quedado para siempre en los periódicos y a ellos tenemos que acudir para encontrarlos. Hay en los periódicos artículos valiosos sobre Fray Luis. En cualquier caso, nos sirven para conocer lo que sobre él se pensaba y la estimación que de él se hacía.

El despojo sistemático de algunas colecciones, de la Biblioteca Románica Hispánica, por ejemplo, nos daría también resultados muy interesantes. Unas cuantas páginas, a veces solo una, pueden iluminarnos más que todo un libro.

Habría que aspirar a una bibliografía crítica, dando en cada papeleta un resumen de su contenido y un juicio de valor sobre el mismo. Sé que la tarea es muy difícil y que puede crear odios y enemistades. Ante ello, quizá sea preferible, si el libro logra nuevas ediciones, dar, en sección aparte, una bibliografía seleccionada, con una brevísima valoración de cada uno de los libros o artículos citados. Como lo ha hecho Manuel Durán en su Fray Luis de León (Twayne, New York 1971). Con o sin juicios de valor, una selección bibliográfica es imprescindible como orientación. De lo contrario, correrá la misma suerte que gran parte de las bibliografías: que son los libros que 
menos se consultan. El especialista sabe cómo arreglárselas él solo y el principiante se encuentra perdido en la selva, con el peligro de que le den gato por liebre. En 1.505 papeletas sobre Fray Luis hay de todo.

En el índice onomástico faltan algunos nombres y esto me ha hecho enormemente difícil la tarea de compulsar mis papeletas con las suyas en busca de las posibles lagunas. No figuran, por ejemplo, Ramón Castelltort ni Carlos García Gual. Pero en las entradas sí se recoge la edición que aquel hizo de La perfecta casada o la que hizo éste sobre la versión en tercetos de El libro de Job. He leído minuciosamente todas las papeletas. Creo que ninguna de las que doy a continuación están recogidas aquí.

Algunos nombres están mal escritos. Aparte de las erratas fácilmente corregibles, hay otras más difíciles de identificar. A veces se repiten en el índice y en las fichas. No figuran en el índice Gloria Durántez y Quima Romagosa, que en la papeleta 377 aparecen como Gloria Quima y Romagosa Durante. En las papeleta y en el índice se repite el nombre de Alonso Shöckel (sic), que debe escribirse Alonso Shökel.

Echo en falta un buen índice de materias. Quien quiera estudiar La perfecta casada o alguna de las obras de Fray Luis encontrará orientación segura en el índice general. Lo mismo para ciertos temas muy generales: filosofía, teología, espiritualidad... Pero, aparte de que estos temas no se excluyen entre sí, sino que se entrecruzan, ¿qué hará quien quiera estudiar la noche, el mar, el campo, la música, la pintura, la Cábala..., y tantos y tantos otros temas de Fray Luis? Pues leerse pacientemente todas las entradas para ver si hay algo escrito sobre la materia que le interesa.

Un índice exhaustivo de materias y una bibliografía seleccionada serán imprescindibles en nuevas ediciones.

La labor más difícil está hecha y bien hecha; muy bien hecha. La presentación, excelente. El nombre de Fray Luis, el interés que su obra sigue despertando, el nivel alcanzado por los estudios a él dedicados... hacen concebir esperanzas halagüeñas y es de desear que el autor siga recogiendo la bibliografía y el libro tenga nuevas ediciones. Fray Luis se lo merece y Rafael Lazcano ha demostrado que sabe hacerlo.

Como complemento, doy algunas papeletas que no he encontrado registradas. Todas anteriores a 1990, fecha de publicación del libro. Sigo el mismo orden del autor. 
II. FUENTES BIBLIOGRÁFICAS

1981

1. Aguilar Piñal, F., Índice de las poesías publicadas en los periódicos españoles del siglo XVIII (=Cuadernos Bibliográficos 43), Consejo Superior de Investigaciones Científicas, Madrid 1981.

Es verdad que el libro de $\mathrm{M}^{\mathrm{a}}$ Teresa Bautista Malillos, citado en la entrada 6, recoge todas las poesías originales de Fray Luis citadas por Aguilar Piñal, pero no las imitaciones que se hicieron de él en el siglo XVIII y éstas también hay que tenerlas en cuenta.

1989

2. Cartapacio de Francisco Morán de la Estrella, Prólogo de Juan Bautista Avalle-Arce, Edición de Ralph, A. di Franco, José J. Labrador Herráiz, C. Ángel Zorita, Editorial Patrimonio Nacional, Madrid 1989.

Francisco Morán de la Estrella, poeta y recopilador de poesías. Su cartapacio reúne poesías de entre 1552 y 1582 , algunas de Fray Luis.

\section{EDICIONES DE LAS OBRAS}

1.5. Poesías

3. Fray Luis de León. Poesía, selección, estudio y notas de J. M. Alda Tesán (=Biblioteca Clásica Ebro 4), Editorial Ebro, Zaragoza 1975, $10^{\mathrm{a}}$ edición (en las papeletas no se recoge ninguna edición).

Está hecha sobre la de Llobera. Numerosas notas aclaratorias.

\section{EsTuDIOS}

1. Generales

1974

4. Rodríguez, JuAn CARlos, Teoría e historia de la producción ideológica. Las primeras literaturas burguesas (siglo XVI), Akal Editor, Madrid 1974, 243-285.

1976

5. Curtius, ERnst Robert, Literatura europea y Edad Media latina, 2 vols. Fondo de Cultura Económica, México 1976, passim (cf. Índice analítico).

1986

6. Revuelta Sañudo, Manuel, y Morón Arroyo, Ciriaco (edic. de), El erasmismo en España, Ponencias del Coloquio celebrado en la Biblio- 
teca de Menéndez Pelayo del 10 al 14 de junio de 1985, Sociedad Menéndez Pelayo, Santander 1986.

No hay ninguna ponencia sobre Fray Luis, pero sí referencias en varias, y todas ellas interesan como contexto.

1989

7. Fernández Álvarez, Manuel, La sociedad española en el Siglo de Oro, Editorial Gredos, Madrid 1989, t. I, 172-177 y $521-547$.

5. Lenguaje

1972

8. Cuevas García. Cristóbal, La prosa mística. Fray Bernardino de Laredo, Universidad de Granada 1972, en especial pp. 62-64.

7. Poesía

1964

9. QUILIS, ANTONIO, Estructura del encabalgamiento en la métrica española, Consejo Superior de Investigaciones Científicas, Madrid 1984, 88-92.

1983

10. Rivers, Elías L., Fray Luis de León. The Original Poems (=Critical Guides to Spanish Text), Tamesis Books Ltd 1983.

8. De los nombres de Cristo

1942

11. Cuevas, E., Fray Alfonso de Mendoza, agustino, primer tratadista de Cristo Rey, La Ciudad de Dios 154 (1942) 333-362.

1951-1952

12. LIDA DE MALKIEL, $\mathbf{M}^{\text {a }}$ RosA da algunas observaciones sobre los nombres de Cristo en Romance Philologhy, V (1951-52) 113-114.

Cit. por Ernst Robert Curtius, Literatura europea y Edad Media latina, 2, México 1976, 698 n. 15.

1974

13. LÓPEz Estrada, Francisco, Los libros de pastores en la literatura española. La órbita previa (=Biblioteca Románica Hispánica. II. Estudios y Ensayos 213), Editorial Gredos, Madrid 1974, 117-121. y 197-205. 
9. La perfecta casada

1988

14. LobAto, M. LuISA, El ideal de la mujer en los escritores doctrinales agustinos de los siglos XVI y XVII, Revista Agustiniana 29 (1988) 725-726.

10. Estudios bíblicos

10.2. El cantar de los Cantares

1981

15. Tibón, Gutierre, El ombligo como centro cósmico, Fondo de Cultura Económica, México 1981, 349=364.

14. Espiritualidad y mística

1937

16. BAYER, R., Les thèmes du néo-platonisme et la mystique espagnole de la Renaissance, en Hommage a Martineche, Paris 1937, 59ss.

1938

17. Brent, Willian Albert, The mysticisme of Luis de León, Oklahoma Thesis 1938, 1941, 94.

1943

18. André, RenÉ, Le mysticisme de Fr. L. de L., Vie Sp 272 (1943) 94-96.

Las tres últimas papeletas están tomadas de SÁINZ RodrígueZ, PEDro, Introducción al estudio de Fray Luis de León, en GuY AlaIN, El pensamiento filosófico de Fray Luis de León, Ediciones Rialp, Madrid 1960, 68 n. 12.

1972

19. Cuevas García, El pensamiento del Islam. Contenido e historia. Influencias en la mística española, Istmo, Madrid 1972, 295-297.

1951-1954

20. WELSH, ROBERT J.,

El libro de Welsh, recogido en la entrada 1353 , fue reseñado con observaciones importantes por P. M. Álvarez, La ciudad de Dios 163 (1951) y por A. Zorita, RET 14 (1954).

1957

21. Sclaflert, C., L'allégorie de la bûche inflammé dans Hugues de Saint Victor et dans Saint Jean de la Croix, RAM 33 (1957) 241-263.

En Pedro Sáinz Rodríguez, loc. cit. 
17. Influencia y difusión

1956

22. Bousoño, Carlos, La poesía de Vicente Aleixandre (=Biblioteca Románica Hispánica II. Estudios y ensayos 27), Editorial Gredos 1956, 371.

Niega la tesis de Vicente Gaos (cf. la entrada 1444), aunque considera que son evidentes los contagios entre Aleixandre y Fray Luis.

\section{9}

23. Avalle-Arce, JuAn Bautista, La novela pastoril española, Revista de Occidente, Madrid 1959, 10-14. Hay edición posterior

\section{2}

24. Casalduero, Joaquín, Sentido y forma de las novelas ejemplares (=Biblioteca románica Hispánica. II. Estudios y Ensayos 57), Editorial Gredos, Madrid 1962, 69-75, 84-87 y 249-253.

Jose VEGA 